\title{
Numerical Methodology to Minimize Resolution and Sensitivity Effects in P-Wave Measurements
}

REFERENCE: Amaral, M. F., Viana da Fonseca, A., and Rios, S., "Numerical Methodology to Minimize Resolution and Sensitivity Effects in P-Wave Measurements," Geotechnical Testing Journal, Vol. 36, No. 2, 2013, pp. 1-9, doi:10.1520/GTJ20120111. ISSN 0149-6115.

\begin{abstract}
This paper presents a new numerical methodology aiming at facilitating the identification of seismic wave's propagation time, using a time domain approach. The solution uses first- and second-order differential computing, namely divided differences methods. Results of extensive laboratory seismic wave tests over aggregate-cement mixtures with different voids ratios (densities) and cement contents (1\%, $2 \%, 3$ $\%, 4 \%$, and $5 \%$ ) are discussed. The results indicated relevant differences in values of longitudinal modulus (or P-wave modulus) derived with and without this methodology. This was considered especially important in stiff specimens with high-seismic wave velocities and low-energy input signals.
\end{abstract}

KEYWORDS: seismic wave tests, aggregate-cement mixtures, voids-cement ratio, signal numeric analysis, signal energy analysis

\section{Introduction}

Signal analysis, and especially signal analysis for seismic wave interpretation, is a difficult task. In geotechnical engineering, several authors (e.g., Viggiani and Atkinson 1995; Brignoli et al. 1996; Greening and Nash 2004; Leong et al. 2005; Arroyo et al. 2006; Alvarado and Coop 2012) have reported difficulties in signal interpretation for soil dynamics purposes, using bender elements (BE) tests. On the other hand, other authors (e.g., Khan et al. 2006, 2011; Tallavó et al. 2009, 2011; Amaral et al. 2011a) have implemented signal transformation techniques to evaluate soil dynamic properties using piston-type ultrasonic transducers. In any case, most of these works report the effect of the subjective interpretation on the obtained results, and, therefore, the operator experience has an important role in these analyses. Arroyo et al. (2010) have described the results obtained by a group of selected specialists (whose results were treated later by statistical methods) to validate bender elements test results.

The great advantage of using BE in geotechnical engineering (Shirley and Hampton 1978) is their ability to adapt to current laboratory apparatus. However, ultrasonic transducers provide much cleaner signals and they are much easier to use than BE (Amaral et al. 2011b). Consequently, it is not surprising that most complex methods - involving Laplace, Fourier, or Z transforms or even the Prony method (Tallavó et al. 2011) - frequently use results from ultrasonic transducers instead of BE. In addition to the alternative frequency domain method for signal treatment, there are others, equally important, which require less numerical effort such as the $\pi$-points identification method (Brocanelli and Rinaldi 1998), the

Manuscript received October 23, 2012; accepted for publication December 3, 2012; published online January 24, 2013.

Univ. of Porto (FEUP), Dept. of Civil Engineering, Portugal. continuous sweep method (Greening et al. 2003), and the group velocity identification method (Graff 1991).

For time domain signal interpretation, several methods have been proposed, including recommendations related to the excitation shape and frequency of the input wave, which effect was proved to have a direct influence in the obtained results (Viana da Fonseca et al. 2009a).

This paper presents an innovative technique which corrects the time of propagation interpreted in time domain for limited resolution and sensitivity in the data-acquisition system. The method presented in this paper, represents a non-complex numerical signal analysis in the time domain by using compression ultrasonic transducers in the laboratory. This new method introduces a new variable (usually not taken into account on signal interpretation), because it deals not only with the equipment resolution and sensitivity, but also with the influence of the selected amplification. Amplifications may be in power (usually located before the specimens) or in scale (placed after the specimens).

This study summarizes the most current methods of signal interpretation in the time domain, using the most simple of them, based on the first break of the received signal. Changes in the received signal because of the signal energy were evaluated by the divided differences method (DDM) of first and second order. In addition, an index proposed by Consoli et al. (2007) and used by Viana da Fonseca et al. (2009a), Consoli et al. (2009, 2011), Amaral et al. (2011a), and Rios et al. (2012), was applied, which relates porosity and cement content. In that sense, the values of the longitudinal or P-wave modulus $\left(M_{0}\right)$ obtained with and without the DDM were plotted against that index. This paper uses a cemented aggregate to prove how this methodology can minimize the effects of resolution and sensitivity, because these effects are more evident on geomaterials with higher seismic wave velocities. Little changes in the propagation time results in considerable 
changes in the seismic wave velocities of stiff (elastic modulus) and light (density) materials. For the same reason, P-wave measurements were used because they have the fastest elastic waves.

Few studies of the dynamic behavior of cement aggregates by ultrasonic testing were found in the literature, which should be because of problems associated with the heterogeneity of wave propagation on these specimens (Landis and Shah, 1995), making its interpretation quite difficult. Landis and Shah (1995) reported these mixtures as somewhat ill-suited as conductors of stress waves, and therefore the interpretation of ultrasonic data is difficult. However, some good results were obtained in these type of materials (LeQuang et al. 2002) when innovative piezoelectric sensors were used.

\section{Existing Time Domain Methodologies for Evaluation of Propagation Time}

\section{First Direct Arrival of the Output Wave}

The direct measurement of the time interval between the input and output waves is the most immediate interpretation technique, being typically used in field geophysical testing (Dyvik and Madshus 1985; Jovičić et al. 1996; Pennington 1999). According to Arulnathan et al. (1998), the first break in the received signal reflects the arriving of the direct plane wave-fronts and is absent of any reflected or refracted waves.

Viana da Fonseca et al. (2009b) identified several phenomena involved in $\mathrm{BE}$ testing that influence and distort the $\mathrm{BE}$ response signal. The authors suggest the display of the complete signal waveform, to define the signal polarization in terms of the relative position of transducers, while sending multiple pulses of different frequencies to eliminate any doubts.

\section{Time Interval between Characteristic Points of the Input and Output Waves}

In a response signal, there are several characteristic points, such as peaks and zeros, easily identified. According to Viggiani and Atkinson (1995) and Arulnathan et al. (1998), in the absence of reflections and refractions, these points can be representative of the seismic wave propagation time. However, because of the ability of the pulse to transport more than one frequency, to damping and to attenuation, the propagation time depends on the characteristic point, increasing with the distance of the quoted point to the origin. Consequently, this type of analysis is not as reliable as usually assumed. Jovičić et al. (1996) presents a different approach using continuous sine functions and resonant frequencies to avoid the referred limitations.

\section{Cross Correlation of Input and Output Signals}

Another way of measuring the wave propagation time is the definition of the time interval corresponding to the maximum cross correlation of the acquired signals, considering the same hypothesis defined above. Viggiani and Atkinson (1995) indicated the cross-correlation function as a measure of the correlation degree between the two signals. Later, Mohsin and Airey (2003) stated that a finite impulse frequency, along with the response of the material at the same pulse, produces a maximum amplitude in a time translation that is defined as the seismic waves propagation time in that material. Camacho-Tauta et al. (2008), based on Mohsin and Airey (2003), applied a moving time-window algorithm to improve cross-correlation results in BE tests.

However, the cross-correlation method also has some limitations. In BE tests (Mohsin and Airey 2003) or in pulse ultrasonic transducers (Amaral et al. 2011b), the non-linearity of the system can be observed because of reflexive and discontinuous properties, or dispersive medium (or the combination of the three) (Graff 1991; Santamarina and Fam 1997). The observation of amplitude growing after the selected peak is a sign of system non-linearity. In these cases, the application of cross correlation generally gives inconsistent results. The previous conditions were observed in the seismic wave measurements of the cemented aggregate, and therefore this method was not applied.

\section{Experimental Program}

\section{Materials}

The material used in this study was a calcareous aggregate sampled from a quarry in the northern central region of Portugal. The grain size distribution curve of the tested specimen is presented in Fig. 1. This quarry is explored for the application in selected unbound granular materials (UGM) for bases and subbases of transport infrastructures.

The aggregate is classified as clayey gravel by the unified classification system (ASTM D2487) and its specific gravity is 2.73 . From the grain size distribution curve of Fig. 1, an effective diameter $\left(D_{50}\right)$ of $4.1 \mathrm{~mm}$ can be deduced, being the uniformity and curvature coefficients of 875 and 8.25 , respectively. From the soil passed on ASTM sieve No. 40, corresponding to $26 \%$ of the total mass, Atterberg limits were determined obtaining a liquid limit of 31 and a plastic limit of 22. This aggregate has a sand equivalent of 15 and a Los Angeles abrasion index of $30 \%$. The water absorption coefficient is $3.9 \%$ and the CBR value in specimens compacted with 12,25 , and 55 blows has given an average value of $63 \%$.

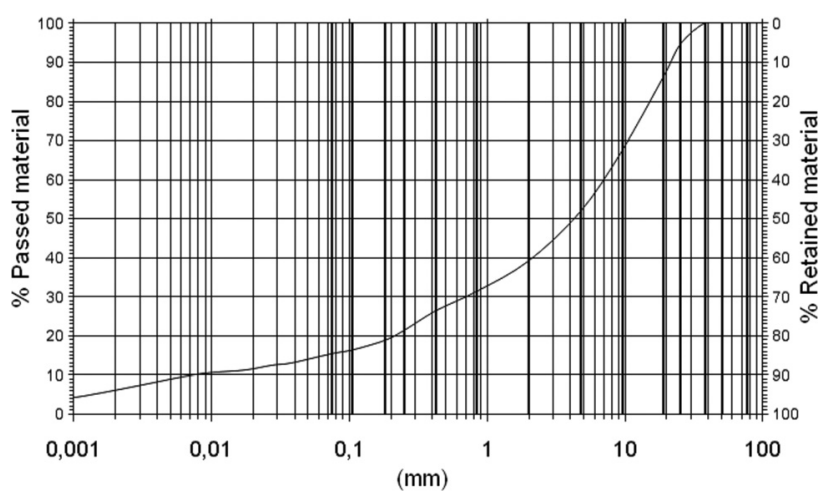

FIG. 1-Grain size distribution curve of the aggregate without cement. 
The maximum soil dry unit weight obtained by the modified Proctor test is $21.4 \mathrm{kN} / \mathrm{m}^{3}$ and the optimum water content is $6.6 \%$ (Fig. 2).

In this study, a type I (CEM I 52.5 R) Portland cement was used whose specific gravity is 3.10 . Being rapid strength cement, it allows a stabilized curing time of around 14 days.

\section{Specimens' Preparation}

The specimens were moulded in cylinders of $150 \mathrm{~mm}$ diameter and $280 \mathrm{~mm}$ height. In the day before moulding, a small portion of soil was taken so that the hygroscopic water content of the soil could be measured ( $w_{\text {hyg }}$ ). Thus, the quantity of water to be added can be easily determined to obtain the desired water content of $6.6 \%$.

The calculation of cement content $(c)$ and water content $(w)$ of the mixture is based on the weight of dry aggregate $\left(W_{a, d}\right)$, as follows,

$$
\begin{gathered}
c=\frac{W_{c, d}}{W_{a, d}} \\
w=\frac{W_{w}}{W_{c, d}+W_{a, d}}
\end{gathered}
$$

where $W_{c, d}$ is the weight of dry cement and $W_{w}$ is the weight of the water in the mixture.

The compaction procedure followed the Proctor compaction is described in ASTM D1557 (2004). However, because the moulded specimens were bigger than the conventional Proctor moulds, the number of blows was calculated so that the Proctor energy was kept constant. Following ASTM D1557 (2004), the expression that gives the compaction energy $\left(E_{p}\right)$ for a given mould volume $(V)$ is written as,

$$
E_{P}=\frac{n \cdot N \cdot W_{P} \cdot H_{P}}{V}
$$

where $n$ is the number of compaction layers, $N$ is the number of strokes per layer, $W_{P}$ is the weight of surcharge, and $H_{P}$ is the falling height of surcharge. Using the Proctor compaction energy and the Proctor number of blows (55), the number of layers was determined for the specimen volume, giving nine layers.

Keeping this number of layers, the specimens were moulded changing the void ratio $(e)$ and the cement content $(c)$. The desired porosity was obtained by changing the number of blows in the

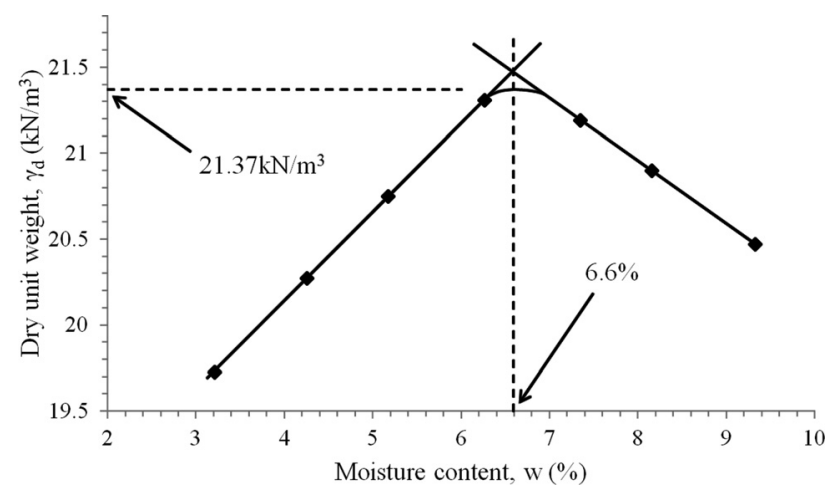

FIG. 2-Modified Proctor curve obtained in the uncemented aggregate. compaction of each layer $(N)$, which varied between 12,25 , and 55.

The specimens were considered adequate for testing if they matched the following conditions:

- Dry unit weight $\left(\gamma_{d}\right) \pm 1 \%$ of the reference value,

- Water content $(w) \pm 1 \%$ of the reference value,

- Diameter between $150 \pm 1 \mathrm{~mm}$,

- Height between $280 \pm 1 \mathrm{~mm}$

\section{Equipment Description}

The cylindrical ultrasonic transducers used in this study are made of stainless steel grade 303-S3, and they include three piezoelectric crystals of PZT-4. The bottom crystal is in direct contact with the interior of the bottom face of the housing, whereas the backing layer is a perspex plate with two disk springs back-to-back to compress the crystal stack. To control the transducer vibration, the lower layer absorbs the energy transmitted by the face of the piezoelectric crystal. The acoustic impedances for the elements PZT-4, stainless steel, and perspex are $34.5 \times 10 \mathrm{~g} / \mathrm{cm}^{3} \cdot \mathrm{s}, 45.55 \times 10^{-5} \mathrm{~g} / \mathrm{cm}^{3} \cdot \mathrm{s}$, and $3.06 \times 10^{-5} \mathrm{~g} / \mathrm{cm}^{3} \cdot \mathrm{s}$, respectively (Tallavó et al. 2009). The nominal frequency of the transmitter given by the manufacturer is $82 \mathrm{kHz}$. An electric potential difference induces a compression-extension deformation providing the transmitter vibratory movement.

The function generator (TG1010; Fig. 3(a)) sends a signal directly to the amplifier (manufactured at the University of

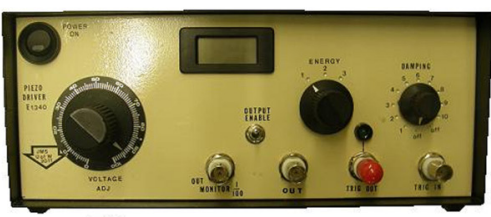

a)

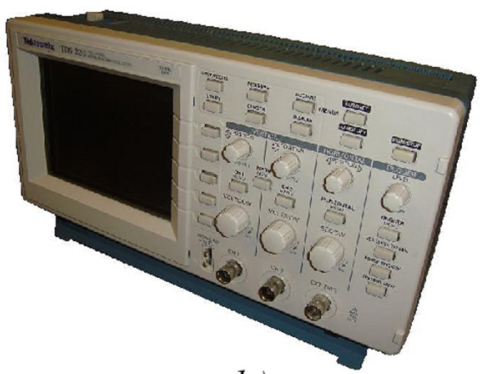

b)

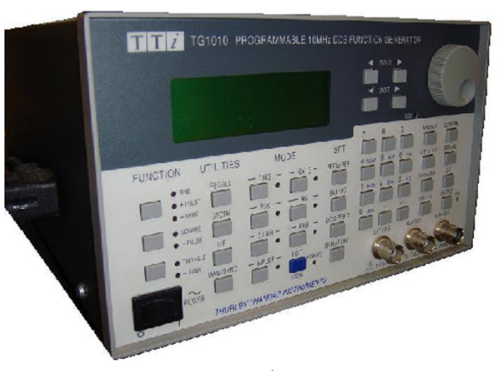

c)
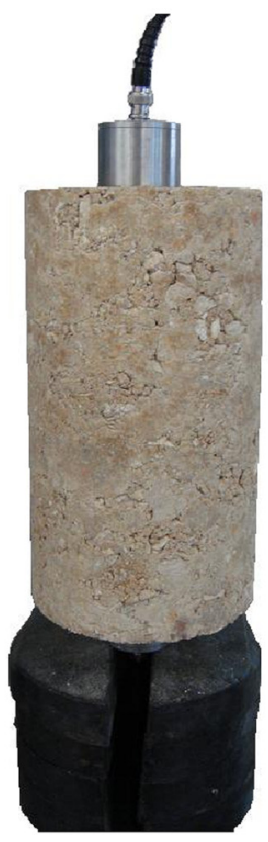

d)
FIG. 3-Equipment: (a) function generator; (b) power amplifier; (c) oscilloscope; and (d) specimen (aggregate mixed with cement) during testing. 


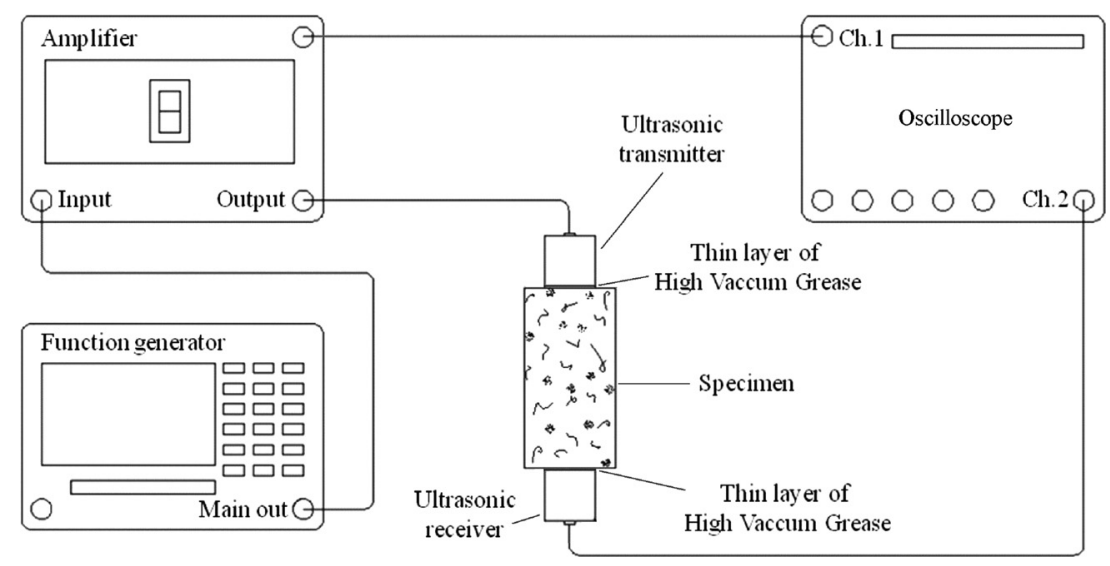

FIG. 4-Scheme of the equipment installation and connections used for the seismic wave measurements.

Waterloo, Canada; Fig. 3(b)) that increases the signal power up to $800 \mathrm{~V}$ and provides an adjustable damping. The transmitted and received signals are also linked to the oscilloscope (Fig. 3(c)), which allows the acquisition of 2500 points per time window.

The system installation and all the necessary connections between the equipment presented in Fig. 3 are illustrated in Fig. 4.

\section{Test Program}

The tests were conducted within $1 \mathrm{~h}$; thus, the loss of humidity was not considered relevant. After curing, the specimens were placed on a base pedestal with an ultrasonic transducer to transmit the input wave, whereas the ultrasonic receiver was placed in the top (Fig. 3(d)), so that $\mathrm{P}$ wave propagates from the bottom to the top. A thin layer of high vacuum grease was used, assuring a good coupling between the transducers and the specimen as indicated in Fig. 4.

The specimens moulding conditions are presented in Table 1, where $\eta$ represents porosity, and $C_{i v}$ is the volumetric cement content, which is the ratio of the volume of cement to the total volume of the specimens. The tests' name includes the cement content,

TABLE 1-Moulding characteristics of the specimens.

\begin{tabular}{lccccc}
\hline & $\begin{array}{c}\text { Water } \\
\text { Specimen }\end{array}$ & $\begin{array}{c}\text { Density, } \\
\text { content, } w(\%)\end{array}\left(\mathrm{kg} / \mathrm{m}^{3}\right)$ & $\begin{array}{c}\text { Void } \\
\text { ratio, } e\end{array}$ & $\begin{array}{c}\text { Porosity, } \\
\eta\end{array}$ & $\begin{array}{c}\text { Volumetric } \\
\text { cement ratio, } C_{\text {iv }}(\%)\end{array}$ \\
\hline M-1\%-12 & 6.3 & 2075 & 0.400 & 0.668 & 0.63 \\
M-1\%-25 & 6.0 & 2199 & 0.318 & 0.466 & 0.67 \\
M-1\%-55 & 5.9 & 2311 & 0.253 & 0.338 & 0.70 \\
M-2\%-12 & 6.5 & 2073 & 0.406 & 0.684 & 1.26 \\
M-2\%-25 & 5.3 & 2169 & 0.329 & 0.490 & 1.33 \\
M-2\%-55 & 5.1 & 2317 & 0.242 & 0.319 & 1.42 \\
M-3\%-12 & 6.4 & 2073 & 0.407 & 0.686 & 1.89 \\
M-3\%-25 & 5.5 & 2226 & 0.299 & 0.427 & 2.04 \\
M-3\%-55 & 5.3 & 2346 & 0.230 & 0.299 & 2.16 \\
M-4\%-12 & 5.4 & 2083 & 0.389 & 0.636 & 2.55 \\
M-4\%-25 & 5.8 & 2197 & 0.322 & 0.474 & 2.68 \\
M-4\%-55 & 5.8 & 2305 & 0.260 & 0.351 & 2.81 \\
M-5\%-12 & 6.3 & 2104 & 0.389 & 0.636 & 3.19 \\
M-5\%-25 & 5.5 & 2194 & 0.322 & 0.474 & 3.35 \\
M-5\%-55 & 5.9 & 2331 & 0.249 & 0.331 & 3.55 \\
\hline
\end{tabular}

immediately after the letter M (material), and the number of blows used in the compaction.

The P-wave velocity was determined by the first direct arrival of the output wave (or first break) being the longitudinal modulus derived from the following expression of the elasticity theory, assuming an elastic behavior (Richart et al. 1970):

$$
M_{0}=V_{P}^{2} \cdot \rho
$$

where $\rho$ is the cemented-aggregate density.

The signal recordings were made using 128 averages eliminating the background noise and consequently the signal disturbance. A square pulse of $82 \mathrm{kHz}$ was used, which is the transducers' nominal frequency.

\section{Current Proposal}

\section{Signal Variation Depending on the Power and Scale Amplification}

The present work describes the results obtained from a reevaluation of the criteria used in the first identification of seismic wave propagation time, exploring the signal output energy. Figure 5 shows that higher amplitude signals led to an identification of lower propagation times, being the offset presented in the figure introduced to facilitate interpretation according to the different applied voltages. It is clear that it is not the P-wave velocity that is affected by the signal energy but the ability of the equipment to detect the wave arrival. This limitation is directly associated with the sensitivity and resolution of the acquisition system, the insufficient energy of the signal, the shape and frequency of the input wave, and the acquisition scale amplitude. It also depends on the experience of the operator in the use of specific equipment.

The analysis presented in Fig. 5 were repeated keeping constant the energy of the input signal and changing the amplification scale of the acquisition equipment, where the same conclusions derived from Fig. 5 were drawn. Therefore, it can be concluded that there is no influence of the amplifier in the time-energy dependence. For that reason, a new method was considered to evaluate the seismic wave propagation time without the previous limitations. However, complications related with overshooting 


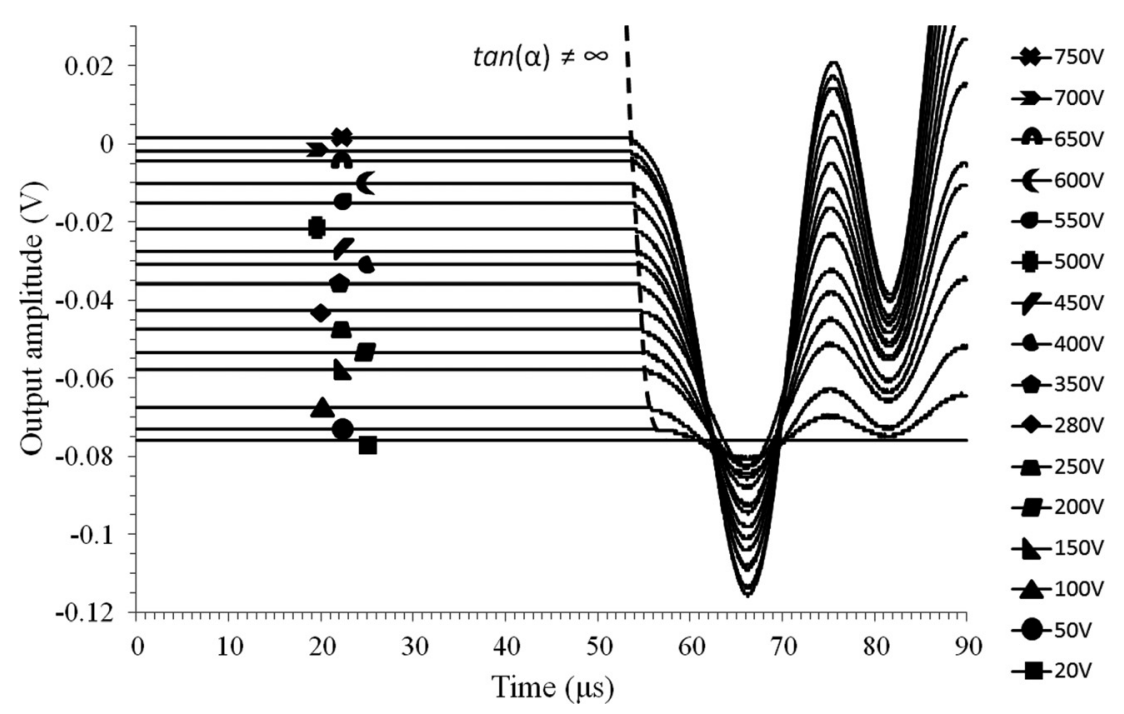

FIG. 5-P-waves propagation time for different energies of the input wave.

(Camacho-Tauta 2010), derived from excessively energized signals that might affect the response signal, were not analyzed in this study.

\section{Divided Differences Method}

The DDM (Hakopian 1981) computes the derivative of $n$th order of a discrete function. In the signal analysis, the divided differences of first order compute the amplitude variation $(A)$ as a function of time $(t)$, i.e., the slopes of the line segments that link two consecutive acquisitioned points $(i)$ are computed.

$$
\frac{\partial A}{\partial t}=\frac{A_{i+1}-A_{i}}{t_{i+1}-t_{i}}
$$

Applying this method to the higher amplified signal of Fig. 5 (750 $\mathrm{V})$, the signal first derivative is obtained, which is presented in Fig. 6(a). Figure 6(b) shows a scale amplification of Fig. 6(a) aiming to assist the interpretation of Fig. 6(a).

The analysis of Fig. 6(a) leads to very interesting and surprising conclusions, especially in low energized signals. Only three derivative values were found $(-0.2,0$, and 0.2$)$, indicating that there are no signal voltage increments higher than the minimum (see Fig. 6(b)). This reveals the lack of resolution and sensitivity of the system to measure seismic wave velocities. The sensitivity and resolution are different variables that usually have distinct treatments. However, it is not the aim of this work to treat them separately; the idea of this work is to overcome both limitations by the extrapolation of the propagation time.

Discretising the response signal and increasing the scale of the graph, as illustrated in Fig. 6(b), it is observed that for each voltage level, there is more than one consecutive point acquired, which explains the shape of the first derivative graph presented in Fig. 6(a).

The DDM allows the calculation of the second derivative of the response signal, using Eq 5 and calculating its time derivative. In the signal of Fig. 6 , the second derivative has a similar shape to a triangular wave (defined by 4 points) with positive polarity (when the signal increases) and negative polarity (when the signal is decreasing). The instant in time where a higher density of these triangles appears indicates an inflection point in the specimen's primitive elastic response.

\section{Assumptions and Formulation}

In the first part of the paper, the selection of the method that uses the first direct arrival of the output wave was explained, and the

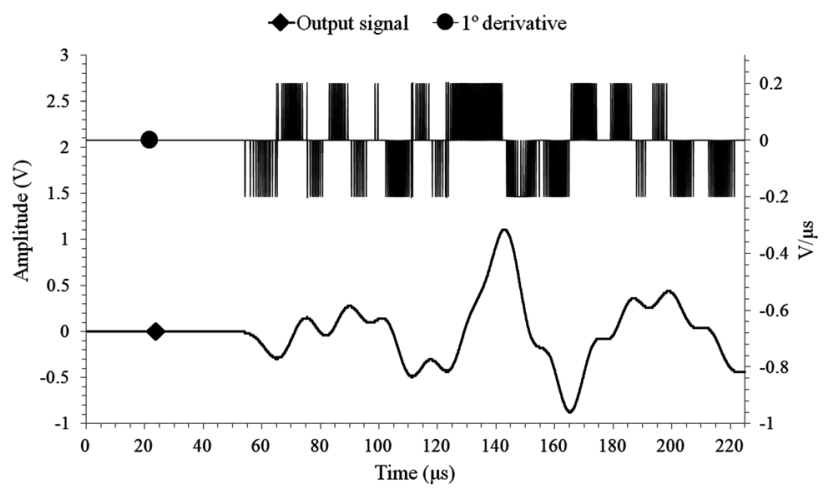

a)

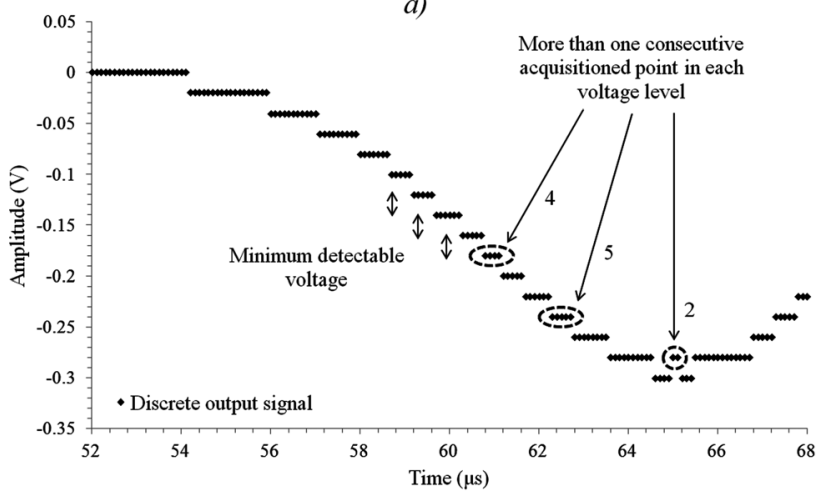

b)

FIG. 6-Divided differences method applied to the signal response: (a) output signal and its first derivative; and (b) zoom of the input signal where discrete points can be observed. 
need for the DDM has also been outlined above. It was highlighted that the different propagation times, derived from the lack of energy in the input signal, should justify the need for a numerical formulation that could minimize the reported problems.

In the present proposal, it is suggested that the P-wave propagation time $\left(t_{P}\right)$, for each measured energy, should correspond to the first point with a derivative different from zero $(\partial A / \partial t \neq 0)$ by the divided difference method.

To define a criterion related to the signal amplitude, another characteristic point is needed that can be related with voltage and allowing simultaneously the model convergence. Using the second-order divided differences, a characteristic point in the first inflexion point (change in concavity, $\partial^{2} A / \partial t^{2}=0$ ) was defined. The reason for this selection (instead of the first peak point) was the instability of the signal derivative in the function peaks clearly observed in Fig. 6(b).

The absolute value of the slope of the secant line that links the two defined characteristic points $\left(\partial A / \partial t \neq 0\right.$ and $\left.\partial^{2} A / \partial t^{2}=0\right)$ is directly associated with the amplitude of the response signal. Figure 7 presents the different secant lines of the signals presented in Fig. 5 , whose angle with horizontal is designated $\alpha$.

It has been observed that the propagation time reduces with increasing energy. Considering the increase of energy, the limitations derived from the lack of resolution and sensitivity are minimized, and it can be assumed that with an infinite energy, a closer value to the real propagation time should be obtained. This value is defined in this paper as the final P-wave time of propagation $\left(t_{P}^{f}\right)$. Because it is not physically possible to have a seismic response with infinite amplitude, an extrapolation of the final propagation time is needed.

It is suggested that the final propagation time $\left(t_{P}^{f}\right)$ is the time instant where $\tan (\alpha)=\infty$. Mathematically, $t_{P}^{f}$ corresponds to a vertical asymptote calculated by the hyperbolic regression of the experimental data. The basic equation of a hyperbolic function is represented by the following expression:

$$
y=\frac{1}{f(x)}+b
$$

where, in this case, $y=\tan (\alpha), x=t_{P}$, and $b$ is a constant. For a signal amplitude close to zero $(0 \mathrm{~V})$, it is not possible to identify

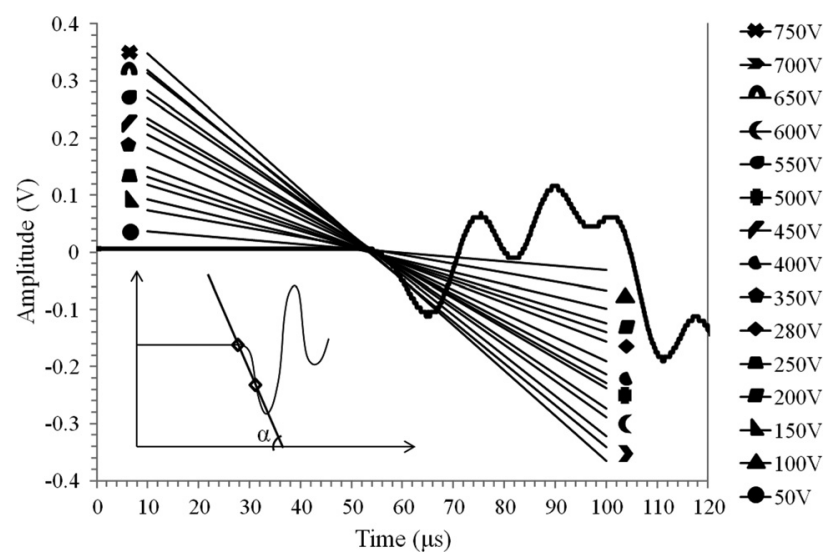

FIG. 7-Secant lines for the signals obtained with different input energies and definition of the secant line linking two characteristic points.

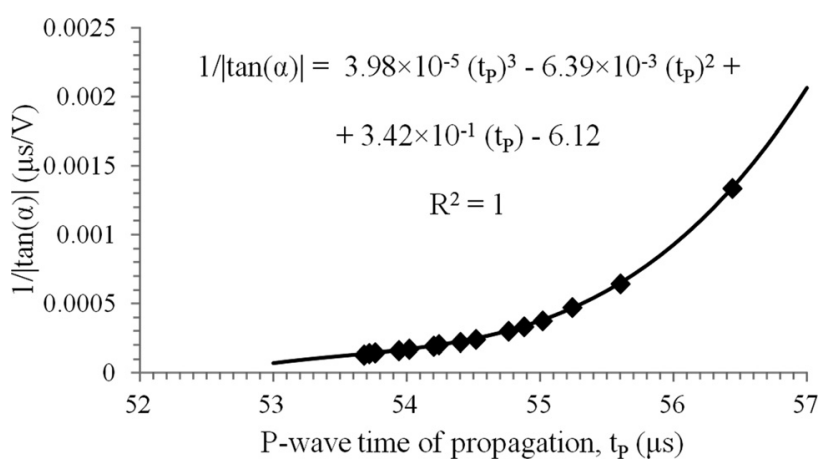

FIG. 8-Cubic regression of $1 / / \tan (\alpha) /$ against $t_{P}$.

any propagation time (i.e., $t_{P}=\infty$ ). This has a mathematical meaning in the sense that a value of $A=0 \mathrm{~V}$, there is a horizontal asymptote of the hyperbolic regression. In this case, $b=0$, and so Eq 6 can simplified as follows,

$$
f\left(t_{P}\right)=\frac{1}{(\tan \alpha)}
$$

Figure 8 represents the absolute values of $1 / \tan (\alpha)$ against $t_{P}$. A third degree equation promotes the regression of these values to the highest possible coefficient of determination $\left(R^{2}\right)$, allowing the definition of $f(x)$

$$
\tan (\alpha)=\frac{1}{k_{1} t_{P}^{3}+k_{2} t_{P}^{2}+k_{3} t_{P}+k_{4}}
$$

where the coefficients $k_{1}, k_{2}, k_{3}$, and $k_{4}$ are indicated in Fig. 8 .

Zero values in the denominator of Eq 8 correspond to asymptotes of that function. At least one of those zeros is real and is equal to $t_{P}^{f}$. The analytical calculation of these solutions might be easily computed by any mathematical software (such as MatLab). The numerical calculation of $t_{P}^{f}$ can be performed creating columns of $t_{P}^{f}$ and $\tan (\alpha)$ values with very small sampling steps, significantly smaller than the Nyquist frequency not to significantly affect $t_{P}^{f}$.

The intersection of the secant lines in point $A(0 \mathrm{~V})$ of Fig. 7 , corresponds to the propagation time $(\partial A / \partial t \neq 0)$ identified in each output signal, which appears to be the same for all the signals. However, Fig. 5 has shown that the propagation time was not the same for all the signals. In Fig. 9, the propagation time $\left(t_{P}\right)$ is represented against the absolute value of the tangent of $\alpha$ where

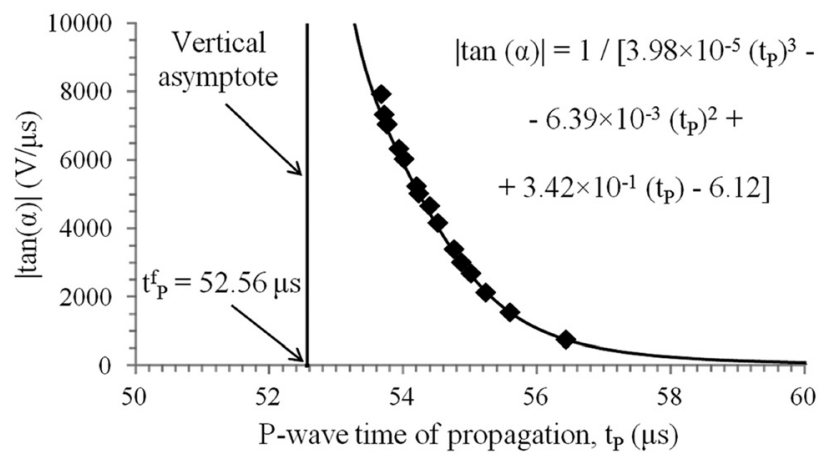

FIG. 9-Graphic evaluation of $t_{P}^{f}$. 
different propagation times can be easily distinguished. The vertical asymptote calculated by the hyperbolic regression of the experimental data corresponds to the desired $t_{P}^{f}$.

The propagation time identified in the impulse wave of $750 \mathrm{~V}$ of amplification presents a significant difference $(2.2 \%)$ to the extrapolated P-wave propagation time $\left(t_{P}^{f}\right)$, assumed as real. The error on the derived longitudinal modulus is greater in specimens with higher seismic wave velocities, which is especially relevant in P-wave velocities (the faster ones), in the generality of the materials, and in cemented geomaterials (with higher stiffness values). In these cases, this analysis becomes extremely important to a correct interpretation of laboratory dynamic properties. The usual time domain interpretation methods systematically provide underestimated values of seismic wave velocities, which might be less relevant if big time windows are used or when seismic wave velocities have low values.

\section{Experimental Results}

The method proposed above applied to the clayey gravel was also analysed using an index called porosity/cement ratio $\left(\eta / C_{\mathrm{iv}}\right)$, which relates the porosity $(\eta)$ with the volumetric cement content $\left(C_{\mathrm{iv}}\right)$. This index was first presented by Consoli et al. (2007) to analyze unconfined compression tests, later proving to be quite adequate to represent small strain stiffness (e.g., Consoli et al. 2009; Amaral et al. 2011a) from seismic wave measurements as included in this paper.

According to the reported works, in the present study, the following relation should be obtained:

$$
M_{0}=k_{5}\left(\frac{\eta}{C_{\mathrm{iv}}^{x}}\right)^{k_{6}}
$$

where $k_{5}$ and $k_{6}$ are constants from the power regression and $x$ represents the empirical variable that maximizes $R^{2}$.

For that purpose, the longitudinal modulus $\left(M_{0}\right)$ of the specimens presented in Table 1 was calculated by Eq 4 using P-wave velocities $\left(V_{P}\right)$ obtained in two different ways: $V_{P}$ computed dividing the distance between transducers by the propagation time $\left(t_{P}\right)$ obtained for an input wave of $750 \mathrm{~V}$, and $V_{P}^{f}$ obtained dividing the same distance by the propagation time obtained by the hereby proposed method, $t_{P}^{f}$. Figure 10 shows the longitudinal modulus obtained by $V_{P}^{f}$ and $V_{P}^{f}\left(M_{0}\right.$ and $M_{0}^{f}$, respectively) plotted together.

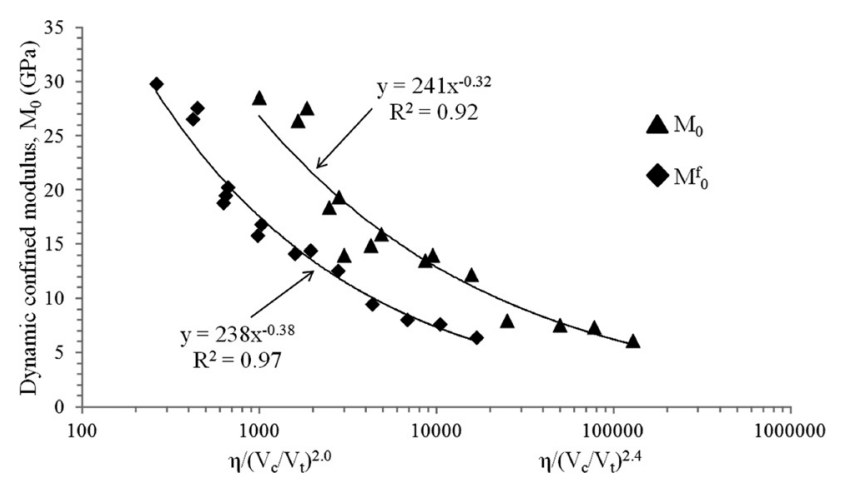

FIG. $10-\mathrm{M}_{0}$ and $M_{0}^{f}$ against $\eta / C i_{v}^{x}$.
The present proposal applied to this experimental data has revealed not only an expected increase in the $M_{0}$ values, but also an improvement in the power regression expressed by a higher $R^{2}$. For these specimens, it represents a difference between $0 \%$ and 6 $\%$ on the longitudinal modulus. Specimens with higher values of $\eta / C_{\mathrm{iv}}{ }^{x}$ show higher differences between $t_{P}$ and $t_{P}^{f}$ because specimens with lower stiffness have lower energized signals leading to a higher distance to the asymptote of Fig. 9.

\section{Conclusions}

In the present work, the longitudinal modulus $\left(M_{0}\right)$ of a calcareous aggregate artificially cemented was analyzed with ultrasonic transducers. During the experimental program, performed with highly energized signals, it was observed that the energy of the excitation pulse had influence in time domain analysis. Low-energy signals lead to more subjective interpretations, whereas high-energy pulses provide signals with a well-defined first break where the propagation time could be identified without major doubts. This problem had a direct influence on the definition of the primary wave propagation time, being that the propagation time $\left(t_{P}\right)$ reduced for higher energized signals.

This fact highlighted the need to look for a new methodology to estimate $t_{P}$ with the maximum energy possible, assuming it to be a more accurate value $\left(t_{P}^{f}\right)$. The change in $t_{P}$ because of the amplitude of the signal was considered a result of the lack of resolution and sensitivity of the equipment and test conditions. Considering the increase in energy, the limitations derived from the lack of resolution and sensitivity are minimized, and the suggested methodology aims to overcome these problems without treating them specifically.

The graphic representation of the observed propagation time against the pulse energy (evaluated by the divided differences method) provided an extrapolation of the propagation time for a signal with infinite energy. The authors believe that this instant, indirectly evaluated, is closer to the real propagation time with minimized resolution and sensitivity effects. However, it is recognized that this methodology, using the divided differences method to derive numerically the characteristics points of the output signal, can only be used with an output signal without noise.

The effects described in this work are usually presented in time domain dynamic analysis, leading to an underestimation of the seismic waves' dynamic modulus. This methodology is especially useful when high values of resonant frequencies condition the wave propagation for dynamic characterization, such as in very stiff materials (e.g., cemented aggregates) generating very low energized signals, and thus significant differences between the directly obtained propagation times $\left(t_{P}\right)$ and the asymptote time $\left(t_{P}^{f}\right)$ correspond to the maximum energy.

Finally, some results were presented on real data over a calcareous aggregate prepared with different void ratios and cement contents by applying this methodology in comparison to the conventional direct evaluation. For the comparison of reproducibility of both methods, the variation of the longitudinal modulus $\left(M_{0}\right)$ obtained from the values of P-wave velocities - and the porosity/ cement ratio $\left(\eta / C_{i v}\right)$ revealed higher coefficient of determination $\left(R^{2}\right)$ of the power regression for the proposed method, indicating that the 
diffusion of the experimental data was minimized. This is a sign that the obtained propagation times are closer to the real values.

\section{Acknowledgments}

The writers acknowledge Dr. Maria do Carmo Coimbra for the mathematical support presented in this paper and to André Domingues for his help with the laboratory work. This research was developed under the activities of FCT (Portuguese Foundation for Science and Technology) research unit CEC, in FEUP through the projects PTDC/ECM/099475/2008, and SIPAV: Innovative Precast Structural Solutions for High-Speed Railway (SI IDT-3440/ 2008), and financed by the European Community (QREN/UE/ FEDER), Operational Program for Competitive Factors "COMPETE."

\section{References}

Alvarado, G. and Coop, M., 2012, "On the Performance of Bender Elements in Triaxial Tests," Géotechnique, Vol. 62, No. 1, pp. 1-17.

Amaral, M. F., Viana da Fonseca, A., Arroyo, M., Cascante, G., and Carvalho, J., 2011a, "Compression and Shear Wave Propagation in Cemented-Sand Specimens," Géotech. Lett., Vol. 1, pp. 79-84.

Amaral, M. F., Viana da Fonseca, A., Carvalho, J., and Consoli, N. C., 2011b, "Dynamic Poisson Ratio Analysis," Proceedings of the 15th European Conference on Soil Mechanics and Geotechnical Engineering, Athens, Greece, September 2011, Vol. 1, pp. 115-120.

Arroyo, M., Muir Wood, D., Greening, P. D., Medina, L., and Rio, J., 2006, "Effects of Sample Size on Bender-Based Axial $G_{0}$ Measurements," Géotechnique, Vol. 56, No. 1, pp. 39-52.

Arroyo, M., Pineda, J. A., and Romero, E., 2010, "Shear Wave Measurements Using Bender Elements in Argillaceous Rocks," Geotech. Test. J. Vol. 33, No. 6, pp. 488-498.

Arulnathan, R., Boulanger, R. W., and Riemer, M. F., 1998, "Analysis of Bender Element Tests," Geotech. Test. J., Vol. 21, No. 2, pp. 120-131.

ASTM D2487, 1998, "Standard Practice for Classification of Soils for Engineering Purposes (Unified Soil Classification System)," Annual Book of ASTM Standards, Vol. 04.08, ASTM International, West Conshohocken, PA.

ASTM D1557, 2004, "Standard Test Methods for Laboratory Compaction Characteristics of Soil Using Modified Effort," Annual Book of ASTM Standards, Vol. 04.08, ASTM International, West Conshohocken, PA.

Brignoli, E. G. M., Gotti, M., and Stokoe, K.H., II, 1996, "Measurement of Shear Waves in Laboratory Specimens by Means of Piezoelectric Transducers," Geotech. Test. J., Vol. 19, No. 4, pp. 385-397.

Brocanelli, D. and Rinaldi, V., 1998, "Measurement of Low Strain Material Damping and Wave Velocity with Bender Elements in the Frequency Domain," Can. Geotech. J., Vol. 35, pp. 1032-1040.

Camacho-Tauta, J., 2010, "Evaluation of the Small-strain Stiffness of Soil by Non-Conventional Dynamic Testing Methods," D.Sc. thesis, Technical University of Lisbon, Portugal.

Camacho-Tauta, J., Ferreira, C., Santos, J., and Viana da Fonseca, A., 2008, "Moving Windows Algorithm to Reduce Uncertain- ties in Bender Elements Testing," Proceedings of the 11th Portuguese Geotechnical National Conference, Coimbra, Vol. 1, pp. 149-156.

Consoli, N. C., Foppa, D., Festugato, L., and Heineck, K., 2007, "Key Parameters for Strength Control of Artificially Cemented Soils," J. Geotech. Geoenviron. Eng., Vol. 133, No. 2, pp. 197-205.

Consoli, N. C., Viana da Fonseca, A., Caberlon Cruz, R., and Heineck, K., 2009, "Fundamental Parameters for the Stiffness and Strength Control of Artificially Cemented Sands," J. Geotech. Geoenviron. Eng., Vol. 135, No. 9, pp. 1347-1353.

Consoli, N. C., Viana da Fonseca, A., Caberlon Cruz, R., and Rios, S., 2011, "Parameters Controlling Tensile Strength of Cement Treated Soils," J. Geotech. Geoenviron. Eng., Vol. 137, No. 11, pp. 1126-1131.

Dyvik, R. and Madshus, C., 1985, "Lab Measurements of $G_{\max }$ Using Bender Elements," Proceedings of the ASCE Annual Convention: Advances in the Art of Testing Soils under Cyclic Conditions, Detroit, pp. 186-197.

Graff, K. F., 1991, Wave Motion in Elastic Solids, Dover Publications, Oxford, UK.

Greening, P. D. and Nash, D. F., 2004, "Frequency Domain Determination of $G_{0}$ Using Bender Elements," Geotech. Test. J., Vol. 27, No. 3, pp. 1-7.

Greening, P. D., Nash, D. F., Benahmed, N., Viana da Fonseca, A., and Ferreira, C., 2003, "Comparison of Shear Wave Velocity Measurements in Different Materials Using Time and Frequency Domain Techniques," Deformation Characteristics of Geomaterials, Proceedings of the 2nd Symposium, I. S. Lyon, H. Di Benedetto, T. Doanh, H. Geoffrey, and C. Sauzeat, Eds., Balkema, The Netherlands, pp. 381-386.

Hakopian, H. A., 1981, "Multivariate Divided Differences and Multivariate Interpolation of Lagrange and Hermite Type," J. Approx. Theory, Vol. 34, No. 3, pp. 286-305.

Jovičić, V., Coop, M. R., and Simic, M., 1996, “Objective Criteria for Determining $G_{\max }$ from Bender Element Tests," Géotechnique, Vol. 46, No. 2, pp. 357-362.

Khan, Z., Majid, A., Cascante, G., Hutchinson, D. J., and Pezeshkpour, P., 2006, "Characterization of a Cemented Sand with the Pulse-Velocity Method," Can. Geotech. J., Vol. 43, pp. 294-309.

Khan, Z., Cascante, G., and El-Naggar, H., 2011, "Dynamic Properties of Cemented Sands Using the Ultrasonic Waves," Can. Geotech. J., Vol. 48, pp. 1-15.

Landis, E. and Shah, S., 1995, "Frequency-Dependent Stress Wave Attenuation in Cement-Based Materials," J. Eng. Mech., Vol. 121, No. 6, pp. 737-743.

Leong, E. C., Yeo S. H., and Rahardjo, H., 2005, "Measuring Shear Wave Velocity Using Bender Elements," Geotech. Test. J., Vol. 28, No. 5, pp. 488-498.

LeQuang, A., Koseki, J., and Sato, T., 2002, "Comparison of Young's Moduli of Dense Sand and Gravel Measured by Dynamic and Static Methods," Geotech. Test. J., Vol. 25, No. 4, pp. 1-20.

Mohsin, A. K. M. and Airey, D. W., 2003, "Automatic $G_{\max }$ Measurements in Triaxial Tests," Proceedings of the 3rd International Symposium on Deformation Characteristics of Geomaterials, pp. 73-80.

Pennington, D. S., 1999, “The Anisotropic Small Strain Stiffness of Cambridge Gault Clay," Ph.D. thesis, University of Bristol.

Richart, F. E., Hall, J. R., and Woods, R. D., 1970, Vibrations of Soils and Foundations, Prentice Hall, Englewood Cliffs, NJ. 
Rios, S., Viana da Fonseca, A., and Baudet, B., 2012, “The Effect of the Porosity/Cement Ratio on the Compression Behavior of Cemented Soil," J. Geotech. Geoenviron. Eng., Vol. 138, No. 11, pp. 1422-1426.

Santamarina, J. C. and Fam, M. A., 1997, "Discussion on Interpretation of Bender Element Tests (Paper by Viggiani and Atkinson, 1995)," Géotechnique, Vol. 47, No. 4, pp. 873-877.

Shirley, D. J. and Hampton, L. D., 1978, "Shear-Wave Measurements in Laboratory Sediments," J. Acoust. Soc. Am., Vol. 63, No. 2, pp. 607-613.

Tallavó, F., Cascante, G., and Pandey, M. D., 2009, "New Methodology for Source Characterization in Pulse Velocity Testing," Geotech. Test. J., Vol. 32, No. 6, pp. 1-16.
Tallavó, F., Cascante, G., and Pandey, M. D., 2011, "Ultrasonic Transducers Characterisation for Evaluation of Stiff Geomaterials," Géotechnique, Vol. 61, No. 6, pp. $501-510$

Viana da Fonseca, A., Caberlon Cruz, R., and Consoli, N., 2009a, "Strength Properties of Sandy Soil-Cement Admixtures," Geotech. Geol. Eng., Vol. 27, No. 6, pp. 681-686.

Viana da Fonseca, A., Ferreira, C., and Fahey, M., 2009b, “A Framework Interpreting Bender Element Tests, Combining Time-Domain and Frequency-Domain Methods," Geotech. Test. J., Vol. 32, No. 2, pp. 1-17.

Viggiani, G. and Atkinson, J. H., 1995, "Interpretation of Bender Element Tests," Géotechnique, Vol. 45, No. 2, pp. 149-154. 